\title{
A Novel Sensitive Bulk Optode Based on 5-Br Salophen as an Ionophore for Determination of Zinc Ion in Real Samples
}

\author{
Elham Alian, ${ }^{a}$ Abolfazl Semnani, ${ }^{*, a}$ Alireza Firooz ${ }^{b}$ and Mahboube Shirani ${ }^{c}$ \\ ${ }^{a}$ Department of Chemistry, Faculty of Science, Shahrekord University, P.O. Box 115, Shahrekord, Iran \\ ${ }^{b}$ Department of Chemistry, University of Isfahan, 8818634141 Isfahan, Iran \\ 'Department of Chemistry, Faculty of Science, University of Jiroft, 7867161167 Jiroft, Iran
}

\begin{abstract}
An optical sensing film was fabricated for sensitive determination of zinc ion in aqueous solutions. The optical sensor was prepared by synthesized ionophore, 5-Br salophen, dioctyl sebacate (DOS) as a plasticizer, sodium tetraphenyl borate (NaTPB) as a lipophilic anionic additive in a poly(vinyl chloride) membrane. The optode response is based on the cation-exchange membrane and indicated a significant absorbance signal change on the exposure to BrittonRobinson buffer solution of $\mathrm{pH} 5.7$ containing $\mathrm{Zn}^{2+}$ ion. The proposed sensor showed a linear range of $4.9 \times 10^{-5}-4.5 \times 10^{-12} \mathrm{~mol} \mathrm{~L}^{-1}$ with a limit of detection of $3.9 \times 10^{-12} \mathrm{~mol} \mathrm{~L}^{-1}$. Furthermore, satisfactory analytical sensing characteristics including selectivity, stability, and reproducibility for the determination of zinc ion were obtained. The response time of the sensing film was less than $5 \mathrm{~min}$, depending on the concentration of $\mathrm{Zn}^{2+}$ ions. The proposed sensor was successfully applied for determination of zinc in tap water, river water, and sea water.
\end{abstract}

Keywords: optical sensor, zinc ion, UV-Vis spectrophotometry, 5-Br salophen

\section{Introduction}

Zinc is essential in human metabolism. It plays an important role in the activity of more than 200 enzymes responsible for genetic materials, food digestion, and metabolism of carbohydrate, protein and fat. The zinc deficiency leads to retarded growth and lower feed efficiency, inhibits the general well-being, and causes ulcers as well as scaling of the skin. ${ }^{1,2}$ Although zinc is necessary for health, excess zinc can be harmful. The excess amount of zinc ion in body significantly decreases copper and iron absorption. Moreover, the free zinc ion in solution is toxic to plants and aquatic organisms. ${ }^{3,4}$ Therefore, due to the pressing need for sensitive zinc determination in biological and environmental samples, particularly water samples, various analytical techniques have been proposed for the determination of zinc. Spectrophotometry, ${ }^{5}$ atomic absorption spectroscopy (AAS), ${ }^{6}$ inductively coupled plasma atomic emission spectrometry (ICP-AES), ${ }^{7}$ solidphase extraction, ${ }^{8}$ liquid-liquid extraction, ${ }^{9}$ dispersive liquidliquid extraction, ${ }^{10}$ ion-imprinted polymer nanoparticle, ${ }^{11}$ nuclear magnetic resonance (NMR) molecular sensor, ${ }^{12}$

*e-mail: a.semnani1341@gmail.com and stripping potentiometry ${ }^{13,14}$ are among the most used techniques. The sample preconcentration, time consuming and complicated operation, and high costs for equipment are some of the drawbacks to these methods. Therefore, these methods are not appropriate for the simple, economical, and sensitive determination of zinc in analysis strategy. In recent years, there has been a growing need for constructing chemical or electrochemical sensors to monitor the environmental samples fast and economically. In this regard, due to their advantages in comparison to ion-selective electrode, optical sensors have received considerable attention. Ease of production, good selectivity and sensitivity, low cost method, as well as high dynamic concentration range, are the main advantages. ${ }^{15-18}$ Bulk optodes are kinds of sensors in which the analyte is extracted into the bulk membrane. For the preparation of an ion-selective optical sensor, an ionophore can be incorporated into a hydrophobic membrane such as a plasticized poly(vinylchloride) (PVC) membrane. Then, the sensor is used in contact with a solution containing a primary ion. ${ }^{19,20}$ Ionophores containing nitrogen atoms such as dithizone, ${ }^{21} 4$-(2-pyridylazo)resorcinol (PAR), ${ }^{22}$ zincon, ${ }^{23}$ 2-(2-hydroxy-5-chloro)benzaldehyde-[4-(3-methyl3-mesitylcyclobutyl)-1,3-thiazol-2yl] hydrazine, ${ }^{24}$ have 
been widely applied in the development of optodes. In this research, the application of synthesized 5-Br salophen as ionophore in PVC membrane containing plasticizer for the sensitive determination of zinc(II) ion in aqueous solutions was investigated. This ionophore can extract $\mathrm{Zn}^{2+}$ from aqueous solution into the organic membrane phase and form a complex. The selectivity and linear dynamic range of this optode is comparable to the previously reported sensors. The sensing membrane has a limit of detection (LOD) lower than the optical sensors mentioned above.

\section{Experimental}

\section{Reagents}

All chemicals are analytical reagent grade. High relative molecular weight PVC, tetrahydrofuran (THF), dibutyl phthalate (DBP), sodium tetraphenyl borate (NaTPB), dioctyl sebacate (DOS), dioctyl phthalate (DOP), and other reagents were purchased from Merck or Fluka. The stock solution of 0.1 mol L-1 $\mathrm{Zn}^{2+}$ was prepared by dissolving appropriate amount of $\mathrm{Zn}\left(\mathrm{NO}_{3}\right)_{2} \cdot 6 \mathrm{H}_{2} \mathrm{O}$ in $100 \mathrm{~mL}$ volumetric flask. The working standard solutions of lower concentration were prepared by suitable dilution of the stock solution with distilled deionized water. The $\mathrm{pH}$ of solutions was adjusted at 5.7 by Britton-Robinson buffer solution. In studying $\mathrm{pH}$ effect, $\mathrm{HCl}$ and $\mathrm{NaOH}$ solutions were used for adjusting the $\mathrm{pH}$. 5-Br salophen, which was synthesized by reaction of 1,2-phenylene diamine and salicylaldehyde in methanol, was used as ionophore in this work. ${ }^{25}$

\section{Apparatus}

An Ultrospec 3100 pro (Cambridge CB4 0FJ England) with a $1.0 \mathrm{~cm}$ cell was used for conventional spectrophotometry. A Jenway $3300 \mathrm{pH}$ meter with a glasscombined electrode was used for the $\mathrm{pH}$ measurements. An atomic absorption spectrometer, Shimadzu model AA670 (Tokyo, Japan), furnished with a Zn-hollow cathode lamp, was also used.

\section{Membrane preparation}

The optimized composition for the preparation of the ion-selective bulk optode consisted of $3.5 \mathrm{mg}$ of $5-\mathrm{Br}$ salophen as ionophore, $60 \mathrm{mg}$ of DOS as plasticizer, $4 \mathrm{mg}$ of NaTPB as additive and $30 \mathrm{mg}$ of PVC. The membrane components were dissolved in $1.5 \mathrm{~mL}$ distilled THF in a glass vial. The solution was shaken vigorously to achieve complete homogeneity. A volume of $40 \mu \mathrm{L}$ of this solution was pipetted and spread on a dust-free glass plate of
$7 \times 5 \mathrm{~mm}$. Then, the membrane was kept in ambient air for $4 \mathrm{~h}$ before use.

\section{Preparation of water sample}

Three drops of nitric acid were added to the water samples and filtered through a Millipore $0.45 \mu \mathrm{m}$ pore size membrane into cleaned polyethylene bottle. After adjusting $\mathrm{pH}$ to 5.7, a defined volume was treated by the recommended procedure for determination of zinc.

\section{Recommended procedure}

The ion-sensing film optode was placed vertically inside a sample cell containing $3 \mathrm{~mL}$ Britton-Robinson buffer solution with $\mathrm{pH}$ of 5.7, and a blank membrane (without ionophore) was put in the reference cuvette containing the buffer solution. After $12 \mathrm{~min}$ (required time to reach the equilibrium), its absorbance was measured at $345 \mathrm{~nm}$. This procedure was repeated for a set of $\mathrm{Zn}^{2+}$ standard solutions at different concentrations. The calibration curve was obtained by plotting their absorbance signal value $\alpha$ (equation 3 ) versus $-\log \left[\mathrm{Zn}^{2+}\right]$. In this way, the unknown $\mathrm{Zn}^{2+}$ concentration contained in the sample was calculated from the calibration curve.

\section{Results and Discussion}

\section{Spectral characteristics of ionophore}

The reaction between 5-Br salophen and zinc ion and the absorbance spectra of the $\mathrm{Zn}$-Br-salophen in both the solution and the membrane are shown in Figures 1 and 2, respectively. Obviously, the spectral properties of the ligand in the membrane are the same as those measured in ethanol solution. Therefore, the wavelength of $345 \mathrm{~nm}$ was used for measuring the absorbance. As it is shown in Figure 3, increasing the concentration of $\mathrm{Zn}^{2+}$ ion makes the absorption intensity of the ionophore decrease at $345 \mathrm{~nm}$ and due to the complex formation between ionophore and zinc ion, a new absorption band appeared at a wavelength of about $415 \mathrm{~nm}$.

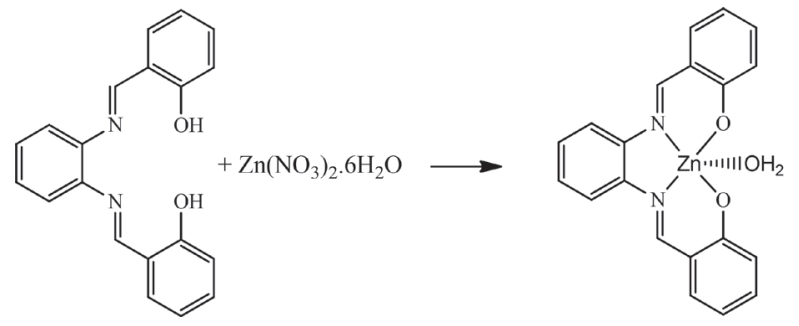

Figure 1. Reaction between 5-Br salophen and $\mathrm{Zn}^{2+}$. 


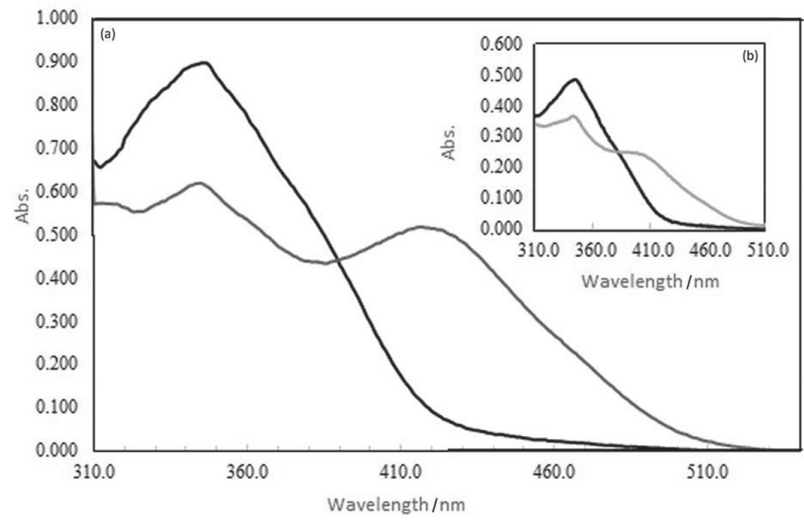

Figure 2. (a) Absorption spectra for $1 \times 10^{-5} \mathrm{M} 5$ - $\mathrm{Br}$ salophen in the presence of $\mathrm{Zn}^{2+}\left(1 \times 10^{-6} \mathrm{M}\right)$ at $\mathrm{pH} 5.7$; (b) absorption spectra of optode film response to $\mathrm{Zn}^{2+}$ in the solution of $1 \times 10^{-6} \mathrm{M}$ at $\mathrm{pH}$ 5.7.

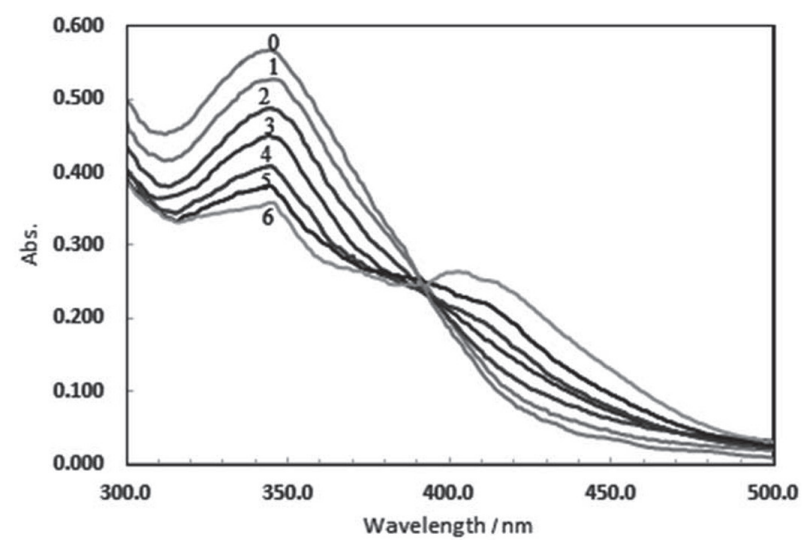

Figure 3. Absorption spectra of the optode at $\mathrm{pH} 5.7$ for $\mathrm{Zn}^{2+}$ concentration of $1 \times 10^{-10}-1 \times 10^{-5} \mathrm{M}$ in which 1-6 refer to $\mathrm{Zn}^{2+}$ concentration and 0 refers to the blank solution (buffer).

\section{Response mechanism and measuring principle}

Absorption spectrum of 5-Br salophen in $\mathrm{Zn}^{2+}$ solution showed a maximum at $345 \mathrm{~nm}$. By adding zinc ion solution, a complex with $\mathrm{H}_{2} \mathrm{~L}$ was formed and its absorbance at $\lambda_{\text {max }}=345$ decreased.

$$
\mathrm{H}_{2} \mathrm{~L}(\text { org })+\mathrm{ZN}^{2+} \rightarrow \mathrm{ZnL}(\text { org })+2 \mathrm{H}^{+}
$$

Considering the formation of a $1: 1$ complex between ionophore and $\mathrm{Zn}^{2+}$ ion in the organic phase, ${ }^{26-29}$ the response mechanism of the proposed optical sensor can be described by the ion-exchange mechanism. As a result of the formation of the complexation equilibrium between $\mathrm{Zn}^{2+}$ ion in the aqueous solution and the ionophore $\left(\mathrm{H}_{2} \mathrm{~L}\right)$ in the organic phase membrane (equation 2), ZnL complex can be formed.

$$
\mathrm{K}_{\mathrm{exch}}=[\mathrm{ZnL}]_{\mathrm{org}}\left[\mathrm{H}^{+}\right]_{\mathrm{aq}}^{2} /\left[\mathrm{H}_{2} \mathrm{~L}\right]_{\mathrm{org}}\left[\mathrm{ZN}^{2+}\right]_{\mathrm{aq}}
$$

The relative absorption intensity, $\alpha$, is the ratio of complexed ionophore in the organic phase, to its total uncomplexed form. Therefore,

$\alpha=[\mathrm{ZnL}]_{\mathrm{org}} /\left[\mathrm{H}_{2} \mathrm{~L}\right]_{\mathrm{org}}=\left(\mathrm{A}-\mathrm{A}_{0}\right) /\left(\mathrm{A}_{1}-\mathrm{A}_{0}\right)$

where $A_{0}$ and $A_{1}$ are the limiting absorbance intensities of the optical sensor at $\alpha=0$ (i.e., uncomplexed $\mathrm{H}_{2} \mathrm{~L}$ ) and $\alpha=1$ (i.e., totally complexed $\mathrm{H}_{2} \mathrm{~L}$ ), respectively. The relationship between $\alpha$-values and the concentration of zinc ions in aqueous solution $\left[\mathrm{Zn}^{2+}\right]_{\mathrm{aq}}$ was obtained from equations 3 and 4 , as follows: ${ }^{27}$

$\alpha /(1-\alpha)=\left(\mathrm{K}_{\mathrm{exch}} /\left[\mathrm{H}^{+}\right]^{2}\right)\left[\mathrm{Zn}^{2+}\right]$

Equation 4 can be used as a basis for the quantitative determination of zinc ions using proposed optical sensor.

\section{Effect of $\mathrm{pH}$}

Equation 4 clearly shows that the sensitivity of the sensor to $\mathrm{Zn}^{2+}$ depends on the $\mathrm{pH}$ of the aqueous solution. This implies that the $\mathrm{pH}$ of the sample solution should be kept invariable using a buffer solution. To find the optimum $\mathrm{pH}$, different concentrations of $\mathrm{Zn}^{2+}$ solutions were prepared at different $\mathrm{pH}$, and the optode responses in contact with those solutions were measured (Figure 4). At the $\mathrm{pH}$ value in the range of 5-6, the working dynamic range reached the highest value. The best result was obtained at $\mathrm{pH}$ 5.7. At higher $\mathrm{pH}$ values, hydroxide ions may react with $\mathrm{Zn}^{2+}$ which leads to a decrease in the response of the optical sensor. The reduction in the optode response at $\mathrm{pH}$ values lower than 5.7 is probably due to the acidic hydrolysis of ionophore under acidic condition. It could be justified by the competition between $\mathrm{Zn}^{2+}$ and $\mathrm{H}^{+}$ions to occupy the active place in the membrane. In fact, an increase in the concentration of $\mathrm{H}^{+}$decreases the exchange rate between $\mathrm{Zn}^{2+}$ and $\mathrm{H}^{+}$at the membrane.

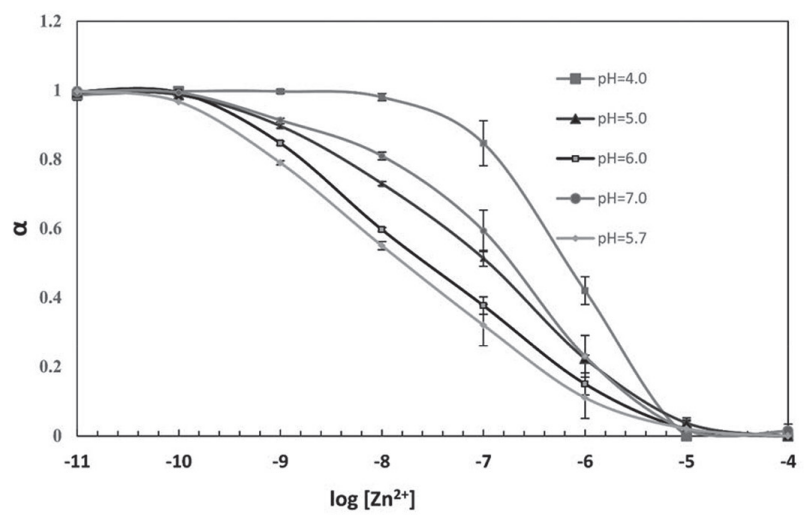

Figure 4. Effect of $\mathrm{pH}$ on the response of membrane in the presence of $1 \times 10^{-11}-1 \times 10^{-4} \mathrm{~mol} \mathrm{~L}^{-1} \mathrm{Zn}^{2+}$ at $345 \mathrm{~nm}$; membrane composition: $3.5 \mathrm{mg}$ of 5-Br salophen, $60 \mathrm{mg}$ of DOS, $30 \mathrm{mg}$ of PVC, $4 \mathrm{mg}$ of NaTPB. 


\section{Choice of plasticizer}

The selectivity and sensitivity for an ionophore depends on the composition of the membrane components. The nature of the plasticizer largely influences the working dynamic concentration range and the response characteristics of the optodes. According to the literature, good ratio of plasticizer to PVC is $2: 1 .^{30-32}$ In order to select the best plasticizer, three membranes were prepared by DOP, DOS, and DBP. The membranes were prepared from a mixture of $30 \mathrm{mg}$ of PVC, $60 \mathrm{mg}$ of plasticizer, $4 \mathrm{mg}$ of additive, and $3.5 \mathrm{mg}$ of ionophore in $1.5 \mathrm{~mL}$ THF. As it is shown in Figure 5a, the membrane containing DOS has a larger response range and better detection limits which implies that this plasticizer makes a homogeneous organic phase and is physically more compatible with the polymer.

\section{Effect of amount of the ionophore}

The optical sensor is based on the incorporation of 5-Br salophen with two hydroxyl functional groups which act as an ion exchanger. This ionophore possesses a double binding property towards $\mathrm{Zn}^{2+}$ in membrane. This ionophore is soluble in organic solvents, while it is insoluble in water. Figure 5b shows the effect of amount of the ionophore on the response of the optical sensor. To find out the best amount of ionophore, three membranes were prepared with the following composition: different amounts of 5-Br salophen with $30 \mathrm{mg}$ of PVC, $60 \mathrm{mg}$ of DOS, and $4 \mathrm{mg}$ of NaTPB. As it is shown in Figure 5b, the membrane containing $3.5 \mathrm{mg}$ of ionophore had the best response of the $\mathrm{Zn}^{2+}$ ion-sensing film. Increasing the amount of the ionophore leads to an increase to the response time of the optical membrane.

\section{Effect of the additive}

The additive makes an easy thermodynamic equilibrium between the membrane and the aqueous solution and consequently makes a rather fast mass transfer of the analyte from the solution into the membrane optode. ${ }^{33}$ Therefore, in the proposed $\mathrm{Zn}^{2+}$ optical sensor, the incorporation of a suitable additive was essential to ensure the fast establishment of the corresponding ion-exchange equilibrium. NaTPB was used as a lipophilic additive for preparing the membrane. The influence of the amount of NaTPB on the membrane response is indicated in Figure 5c. Various amounts of the additive with $30 \mathrm{mg}$ of PVC, $60 \mathrm{mg}$ of DOS, and $3.5 \mathrm{mg}$ of ionophore were used to prepare the membranes. The best result was obtained by the membrane containing $4 \mathrm{mg}$ of NaTPB.
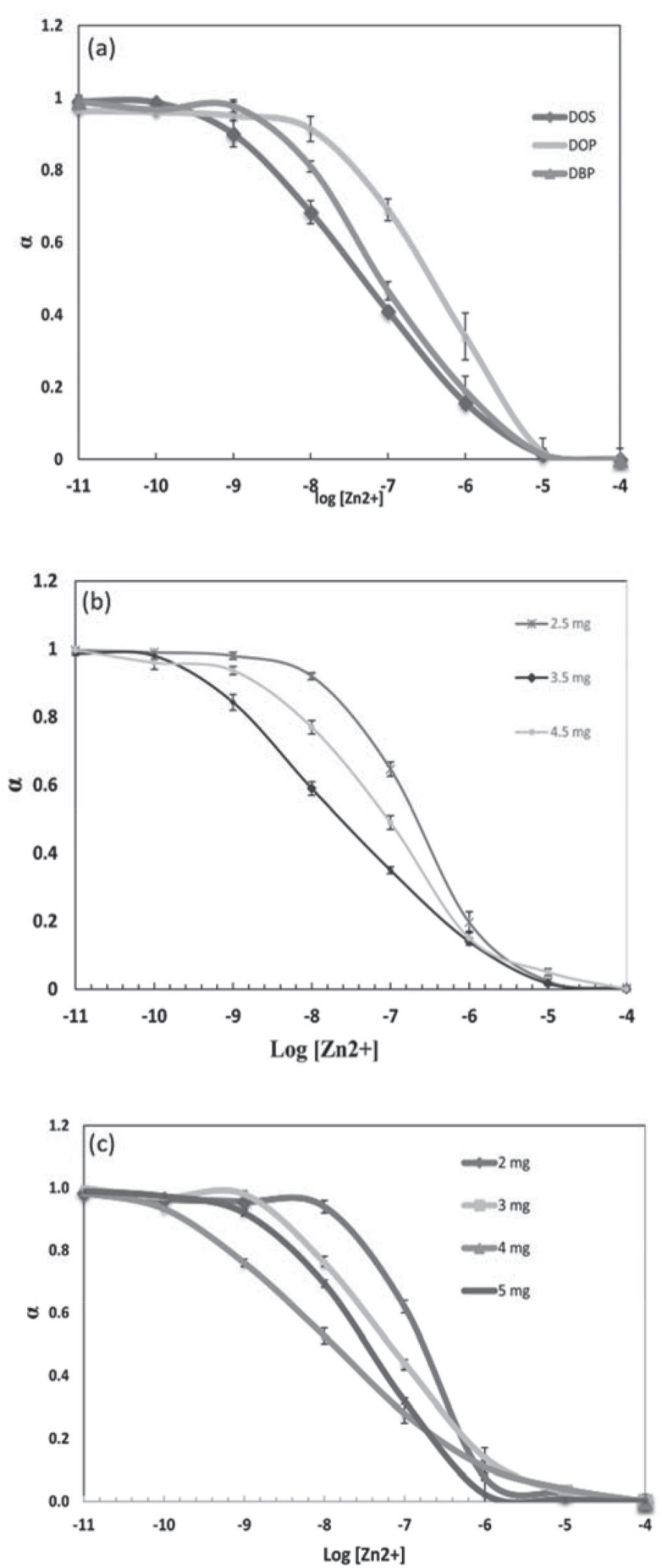

Figure 5. (a) Effect of the type of plasticizer; (b) the amount of ionophore; and (c) the amount of additive on the response of the optical sensing film in aqueous solution with $\mathrm{pH}=5.7$.

\section{Response time}

The response time of the optical sensor is the necessary time for the sensor membrane to attain equilibrium with the sample solution. The period needed to reach the steady state is defined by equation $5 .{ }^{34}$ 
$\mathrm{t}_{95 \%}=1.13 \mathrm{D}^{2} / \mathrm{D}_{\mathrm{m}}$

where $\mathrm{D}_{\mathrm{m}}$ is the diffusion coefficient and $\mathrm{D}$ is the membrane thickness. The response time of the optical sensor was investigated by immersing the proposed sensor in the sample solution and the changes in absorbance at $\lambda_{\max }$ were plotted $v s$. time. Figure 6 represents the response time of 160 and $245 \mathrm{~s}$ for zinc concentration of $10^{-7}$ and $10^{-10} \mathrm{M}$, respectively.

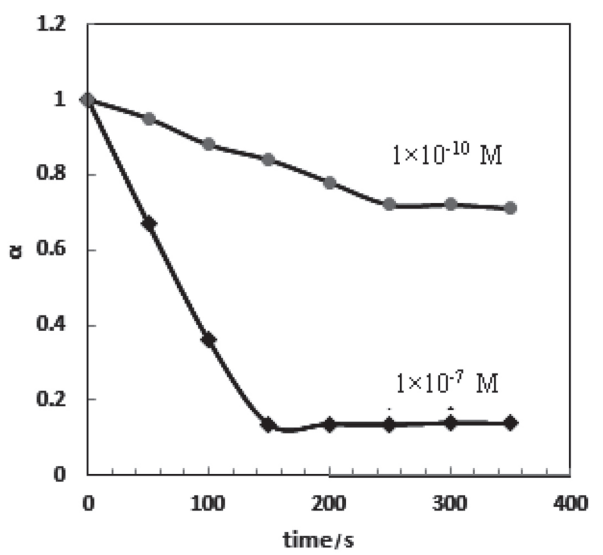

Figure 6. Response time of the optode at $\mathrm{pH}$ 5.7.

\section{Reversibility, reproducibility and short-term stability}

In order to study the regenerability of the membrane, the solution of $0.1 \mathrm{M}$ of $\mathrm{HNO}_{3}, \mathrm{H}_{3} \mathrm{PO}_{4}$, EDTA, $\mathrm{HCl}$, and $\mathrm{KCl}$ were used. It was found that the membrane was not completely regenerated in any of the above solutions.

The reproducibility of the sensor was considered by preparing eight sensors and measuring the absorbance of the solutions of $1 \times 10^{-7}$ and $1 \times 10^{-9} \mathrm{~mol} \mathrm{~L}^{-1} \mathrm{Zn}^{2+}$ ions eight times. The relative standard deviations (RSD\%, $\mathrm{n}=8$ ) of 1.34 and 2.28 were achieved, respectively. To obtain the repeatability of the proposed optode, zinc ion solutions with concentrations of $1 \times 10^{-7}$ and $1 \times 10^{-10} \mathrm{~mol} \mathrm{~L}^{-1}$ were measured eight times by the optical sensor. The obtained RSD\% was found to be 0.45 and 0.47 , respectively.

The short-term stability of the optical sensor was determined by measuring its absorbance in contact with a sample solution containing $1 \times 10^{-7} \mathrm{~mol} \mathrm{~L}^{-1}$. The signal was recorded once an hour at $345 \mathrm{~nm}$ over a period of $4 \mathrm{~h}$ and the RSD\% was equal to 0.95 . These experiments revealed that the optical sensor has an acceptable reproducibility and stability.

\section{Analytical figures of merit}

The optical response of the $\mathrm{Zn}^{2+}$ selective membrane to the various concentrations of $\mathrm{Zn}^{2+}$ under the optimal conditions and $\mathrm{pH} 5.7$ is shown in Figure 3. The optode response $(\alpha)$ depends on the logarithm of the zinc ions concentration in the range of $4.9 \times 10^{-5}$ to $4.5 \times 10^{-12} \mathrm{~mol} \mathrm{~L}^{-1}$ with a correlation equation of $\alpha=-0.141 \log \left[\mathrm{Zn}^{2+}\right]-0.593$ (Figure 7). Low detection limit for this optode was obtained, which was $3.9 \times 10^{-12} \mathrm{~mol} \mathrm{~L}^{-1}$.

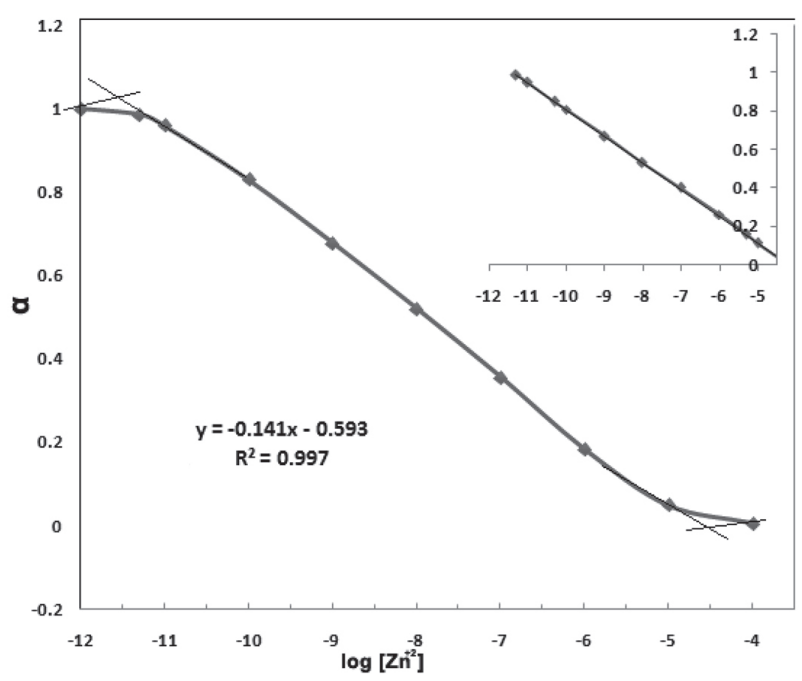

Figure 7. Response signal of the sensor to $\mathrm{Zn}^{2+}$ ions in buffer solution $(\mathrm{pH}=5.7)$ at the optimum conditions.

\section{Selectivity}

The selectivity of the optical sensor, which reflects the relative response of the sensor for primary ion, was investigated over different ions presented in the solution. For this purpose, the interference of common ions on the response of the optical sensor was examined using a certain concentration of zinc solution $\left(1 \times 10^{-7} \mathrm{~mol} \mathrm{~L}^{-1}\right)$. Then, the changes in absorbance before and after adding various interfering ions in the $\mathrm{Zn}^{2+}$ solution buffered were measured at $\mathrm{pH}$ 5.7. The tolerance limit, which is defined as the ratio of the concentration of interfering ion over the concentration of zinc ion that caused a relative error of less than 5\%, was calculated to examine the selectivity. According to the obtained results in Table 1, the zinc ion content of the solution can be selectively determined using the proposed optical sensor.

Table 1. Effect of some foreign ions on the optode response for the determination of $\mathrm{Zn}^{2+}\left(1 \times 10^{-7} \mathrm{M}\right)$

\begin{tabular}{lc}
\hline Interfering ion & Tolerance limit (interferent $/ \mathrm{Zn}^{2+}$ ) \\
\hline $\mathrm{Cr}^{3+}, \mathrm{K}^{+}, \mathrm{Na}^{+}, \mathrm{Cd}^{2+}, \mathrm{Mg}^{2+}, \mathrm{Ca}^{2+}, \mathrm{Al}^{3+}$, & 1000 \\
$\mathrm{Mn}^{2+}, \mathrm{Ag}^{+}, \mathrm{F}^{-}, \mathrm{Cl}^{2}, \mathrm{NO}_{3}, \mathrm{PO}_{4}{ }_{4}^{3-}, \mathrm{SO}_{4}^{2-}$ & \\
$\mathrm{Ni}^{2+}, \mathrm{Pb}^{2+}, \mathrm{Hg}^{2+}$ & 500 \\
$\mathrm{Cu}^{2+}$ & 50 \\
$\mathrm{Fe}^{2+}, \mathrm{Fe}^{3+}$ & 10 \\
\hline
\end{tabular}


Table 2. Comparison of the proposed method with the recent literature for zinc determination

\begin{tabular}{|c|c|c|c|c|c|c|}
\hline Method & $\mathrm{LR}^{\mathrm{a}} / \mathrm{M}$ & $\mathrm{LOD}^{\mathrm{b}} /\left(\mathrm{mol} \mathrm{L}^{-1}\right)$ & $\mathrm{RSD}^{\mathrm{c}}$ & Reagent & Support & Reference \\
\hline Absorbance & $1.68 \times 10^{-8}-8.40 \times 10^{-8}$ & $6.7 \times 10^{-9}$ & 1.2 & 4-(2-pyridylazo) resorcinol & sol-gel & 22 \\
\hline Absorbance & $0.76 \times 10^{-6}-30.60 \times 10^{-6}$ & $1.6 \times 10^{-7}$ & 2.82 & zincon & triacetylcellulose & 23 \\
\hline Absorbance & $2.5 \times 10^{-8}-5.8 \times 10^{-5}$ & $8.0 \times 10^{-9}$ & 3.5 & dithizone & $\mathrm{PVC}^{\mathrm{d}}$ & 21 \\
\hline Absorbance & $1 \times 10^{-7}-4.03 \times 10^{-6}$ & $5.4 \times 10^{-8}$ & 3.6 & 1,5-diphenylcarbazone & sol-gel & 35 \\
\hline Fluorescence & $5.0 \times 10^{-7}-1 \times 10^{-4}$ & $2.2 \times 10^{-7}$ & 3.2 & $\begin{array}{c}\text { 2-(2-hydroxy-5-chloro)benzaldehyde- } \\
\text { [4-(3-methyl-3-mesitylcyclobutyl)- } \\
\text { 1,3-thiazol-2yl]hydrazone }\end{array}$ & $\mathrm{PVC}$ & 24 \\
\hline Fluorescence & $1.0 \times 10^{-9}-2.0 \times 10^{-3}$ & $8.1 \times 10^{-10}$ & 1.7 & $\begin{array}{l}N, N^{\prime} \text {-bis(salicylaldehyde) } \\
\text { 2,3-diaminonaphthalene }\end{array}$ & $\mathrm{PVC}$ & 36 \\
\hline Fluorescence & $1.0 \times 10^{-10}-1.0 \times 10^{-2}$ & $6.3 \times 10^{-11}$ & 1.6 & $N, N^{\prime}$-bis-(1-hydroxyphenylimine)2,2'-pyridil & $\mathrm{PVC}$ & 37 \\
\hline Absorbance & $4.5 \times 10^{-12}-4.9 \times 10^{-5}$ & $3.9 \times 10^{-12}$ & 2.28 & 5-Br salophen & PVC & this work \\
\hline
\end{tabular}

${ }^{\mathrm{a}} \mathrm{LR}$ : linear range; ${ }^{\mathrm{L}} \mathrm{LOD}$ : limit of detection; ${ }^{\mathrm{c} R S D}$ : relative standard deviation; ${ }^{\mathrm{d} P V C}$ : poly(vinylchloride).

\section{Comparison with other zinc optodes}

A comparison between the proposed method and the previously reported methods for $\mathrm{Zn}^{2+}$ determination is indicated in Table 2. Linear dynamic range, detection limits, sensitivity and selectivity for the determination of desired ion are the most important factors for optical sensors. Hence, based on data in Tables 1 and 2, it was concluded that the proposed optical sensor is comparable to the existing optical sensors. Among the advantages of this work in comparison to the previous optodes (especially those using the method of absorbance), it has wide linear dynamic range, low detection limit, and selectivity.

\section{Application}

The sensor was applied for determination of $\mathrm{Zn}^{2+}$ ion concentration in various water samples. Tap water was collected from a local pipe and this was buffered with Britton-Robinson buffer solution (pH 5.7). The river and sea water were prepared as described in Preparation of water sample section and determined with the optical sensor. The accuracy of the results was also checked by graphite furnace atomic absorption spectrometry (GF AAS). As the results indicated in Table 3, there is no significant difference

Table 3. Determination of zinc in water samples

\begin{tabular}{lccc}
\hline \multirow{2}{*}{ Sample } & \multicolumn{2}{c}{ Concentration of $\mathrm{Zn}^{2+\mathrm{a}}$} & \\
\cline { 2 - 3 } & $\begin{array}{c}\text { Sensor } / \\
(\mathrm{mol} \mathrm{L}\end{array}$ & $\begin{array}{c}\left.\mathrm{G}^{-1}\right) \\
\left(\mathrm{mol} \mathrm{LAS}^{-1}\right)\end{array}$ & \\
\hline Tap water $^{\mathrm{c}}$ & $(1.2 \pm 0.2) \times 10^{-6}$ & $(1.3 \pm 0.1) \times 10^{-6}$ & 0.82 \\
River water $^{\mathrm{d}}$ & $(3.9 \pm 0.1) \times 10^{-6}$ & $(3.7 \pm 0.1) \times 10^{-6}$ & 2.47 \\
Sea water $^{\mathrm{e}}$ & $(2.9 \pm 0.1) \times 10^{-6}$ & $(3.1 \pm 0.1) \times 10^{-6}$ & 2.47 \\
\hline
\end{tabular}

${ }^{a}$ The results are mean \pm standard deviation $(n=3)$; ${ }^{\text {bF }}$ AAS: graphite furnace atomic absorption spectroscopy; 'from Shahrekord University; ${ }^{\mathrm{d}}$ from Zayanderoud River in Isfahan; ${ }^{\mathrm{e}}$ Caspian sea; $\mathrm{t}_{\text {cal }}$ : calculated $\mathrm{t}$ and $\mathrm{t}_{\text {table }(95 \%, 4)}=2.78$. between the results of the proposed method and that of GF AAS (at $95 \%$ confidence level).

\section{Conclusions}

In this work, an efficient and selective optode was developed for detection and determination of zinc ion at low concentration levels. The proposed optical sensor had the advantages such as facile fabrication process, low cost, as well as short response time. It also shows high dynamic concentration range and low detection limit compared to the previous reported sensors. The sensor was applied successfully for the determination of $\mathrm{Zn}^{2+}$ ion in tap water, river water, and sea water.

\section{Acknowledgments}

The financial support of this work provided by Shahrekord University is highly appreciated. The authors are also partially supported by the Center of Excellence for Mathematics, Shahrekord University. The authors are also deeply indebted to Dr A. H. Kianfar with his valuable contribution, without whom this work could never be finished.

\section{References}

1. Liu, R.; Liu, D.; Sun, A.; Liu, G.; Analyst 1995, 120, 569.

2. Vallee, B. L.; Auld, D. S.; Biochemistry 1990, 29, 5647.

3. Rout, G. R.; Das, P. In Sustainable Agriculture; Lichtfouse, E.; Navarrete, M.; Debaeke, P.; Véronique, S.; Alberola, C., eds.; Springer Netherlands: Dordrecht, 2009, ch. 53, p. 873.

4. Fosmire, G. J.; Am. J. Clin. Nut. 1990, 51, 225.

5. Sedaira, H.; Talanta 2000, 51, 39.

6. Cha, N.-R.; Lee, J.-K.; Lee, Y.-R.; Jeong, H.-J.; Kim, H.-K.; Lee, S.-Y.; Anal. Lett. 2010, 43, 259. 
7. Zhao, L.; Zhong, S.; Fang, K.; Qian, Z.; Chen, J.; J. Hazard. Mater. 2012, 239-240, 206.

8. Krawczyk, M.; Jeszka-Skowron, M.; Matusiewicz, H.; Microchem. J. 2014, 117, 138.

9. de Aquino, E. V.; Rohwedder, J. J. R.; Facchin, I.; Pasquini, C.; Talanta 2002, 56, 643.

10. Rajabi, M.; Asemipour, S.; Barfi, B.; Jamali, M. R.; Behzad, M.; J. Mol. Liq. 2014, 194, 166.

11. Shamsipur, M.; Rajabi, H. R.; Pourmortazavi, S. M.; Roushani, M.; Spectrochim. Acta, Part A 2014, 117, 24.

12. Zhang, J.; Jiang, W.; Luo, Q.; Zhang, X.; Guo, Q.; Liu, M.; Zhou, X.; Talanta 2014, 122, 101.

13. Tarley, C. R. T.; Santos, V. S.; Baêta, B. E. L.; Pereira, A. C.; Kubota, L. T.; J. Hazard. Mater. 2009, 169, 256.

14. Dugo, G.; La Pera, L.; Bruzzese, A.; Pellicanò, T. M.; Turco, V. L.; Food Control 2006, 17, 146.

15. Valeur, B.; Leray, I.; Coord. Chem. Rev. 2000, 205, 3.

16. Goyal, R. N.; Oyama, M.; Gupta, V. K.; Singh, S. P.; Sharma, R. A.; Sens. Actuators, B 2008, 134, 816.

17. Gupta, V. K.; Chandra, S.; Lang, H.; Talanta 2005, 66, 575.

18. Gupta, V. K.; Goyal, R. N.; Pal, M. K.; Sharma, R. A.; Anal. Chim. Acta 2009, 653, 161.

19. Prasad, R.; Gupta, V. K.; Kumar, A.; Anal. Chim. Acta 2004, $508,61$.

20. Jain, A. K.; Gupta, V. K.; Singh, L. P.; Srivastava, P.; Raisoni, J. R.; Talanta 2005, 65, 716.

21. Abbasitabar, F.; Zare-Shahabadi, V.; Shamsipur, M.; Akhond, M.; Sens. Actuators, B 2011, 156, 181.

22. Jerónimo, P. C. A.; Araújo, A. N.; Montenegro, M. C. B. S. M.; Sens. Actuators, B 2004, 103, 169.

23. Rastegarzadeh, S.; Rezaei, V.; Sens. Actuators, B 2008, 129, 327.
24. Aksuner, N.; Henden, E.; Yilmaz, I.; Cukurovali, A.; Sens. Lett. 2010, 8, 684 .

25. Ali Hossein, S.; Mohebbi, S.; J. Chem. Res. 2006, 2006, 257.

26. Dalla Cort, A.; Mandolini, L.; Pasquini, C.; Rissanen, K.; Russo, L.; Schiaffino, L.; New J. Chem. 2007, 31, 1633.

27. Gasbarri, C.; Angelini, G.; Fontana, A.; de Maria, P.; Siani, G.; Giannicchi, I.; Cort, A. D.; Biochim. Biophys. Acta 2012, 1818 , 747.

28. Germain, M. E.; Vargo, T. R.; Khalifah, P. G.; Knapp, M. J.; Inorg. Chem. 2007, 46, 4422.

29. Cano, M.; Rodríguez, L.; Lima, J. C.; Pina, F.; Dalla Cort, A.; Pasquini, C.; Schiaffino, L.; Inorg. Chem. 2009, 48, 6229.

30. Firooz, A. R.; Ensafi, A. A.; Hajyani, Z.; Sens. Actuators, B 2013, 177, 710 .

31. Amini, M. K.; Khezri, B.; Firooz, A. R.; Sens. Actuators, B 2008, 131, 470.

32. Bualom, C.; Ngeontae, W.; Nitiyanontakit, S.; Ngamukot, P.; Imyim, A.; Tuntulani, T.; Aeungmaitrepirom, W.; Talanta 2010, 82,660 .

33. Rosatzin, T.; Bakker, E.; Suzuki, K.; Simon, W.; Anal. Chim. Acta 1993, 280, 197.

34. Bakker, E.; Bühlmann, P.; Pretsch, E.; Chem. Rev. 1997, 97, 3083.

35. Samadi-Maybodi, A.; Rezaei, V.; Sens. Actuators, B 2014, 199 , 418.

36. Abdel Aziz, A. A.; J. Lumin. 2013, 143, 663.

37. Abdel Aziz, A. A.; Seda, S. H.; Mohammed, S. F.; Sens. Actuators 2016, 223, 566.

Submitted: March 4, 2017

Published online: September 15, 2017 